\title{
Peutz-Jeghers syndrome: A case report
}

\author{
Pratima Poudel', Roushan Jahan ${ }^{2}$ \\ ${ }^{1}$ Dermatologist, ${ }^{2}$ Consultant Dermatologist, Department of Dermatology, Kanti Children's Hospital, Nepal
}

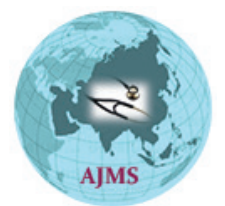

\section{A B S T R A C T}

Peutz-jeghers syndrome is a rare inherited autosomal dominant disease which is characterized by mucocutaneous pigmentation and multiple polyps in the gastrointestinal tract. We report a case of 10 years old female who was referred to us from surgical department for the evaluation of brownish pigmented macules over lips, face, palms and soles. Patient was presented with recurrent abdominal pain along with vomiting and blood mixed stool for a month. Ultrasound of abdomen revealed jejuno-jejunal intussusception for which laparotomy was done during which multiple polyps were visualized. Polypectomy was done and biopsy revealed it to be tubulovillous adenoma. Patient was diagnosed as Peutz-jeghers syndrome as there were multiple polyps in the jejunum along with the characteristics mucocutaneous involvement.

Key words: Intussusception; mucocutaneous pigmentation; Peutz-Jeghers syndrome; tubulovillous adenoma
Access this article online

\section{Website:}

http://nepjol.info/index.php/AJMS

DOI: 10.3126/ajms.v12i7.35064

E-ISSN: 2091-0576

P-ISSN: 2467-9100

Copyright (c) 2021 Asian Journal of Medical Sciences

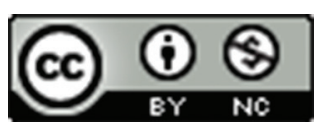

This work is licensed under a Creative Commons Attribution-NonCommercial 4.0 International License.

\section{INTRODUCTION}

Peutz-jeghers syndrome (PJS) is a rare disorder which is characterized by intestinal polyposis as well as pigmentation of the skin and mucous membrane. ${ }^{1}$ This is caused due to the mutation of STK11 gene on chromosome 19p which codes for serine-threonine kinase. ${ }^{2}$ Besides polyposis, there is significantly increased risk of gastrointestinal and extra gastrointestinal malignancy. ${ }^{3}$

The clinicopathological criteria of World Health Organization (WHO) for diagnosing PJS are as follows:

(1) Three or more polyps, with histological features of PJS.

(2) A family history of PJS with any number of polyps.

(3) A family history of PJS with characteristic mucocutaneous pigmentation.

(4) Characteristic mucocutaneous pigmentation with any number of polyps. ${ }^{4}$

\section{CASE REPORT}

A 10 years old female was referred from surgical department to us with the complaints of multiple pigmented lesions over lips involving mucocutaneous junction and bilateral palms and soles. Initially, there were few brownish pigmented pinpoint macules over lower lips 8 years ago. Subsequently, after 3 months similar lesions appeared over bilateral palms and soles. For 2 years there was rapid increase in size and numbers of lesion. On examination, there were multiple discrete to coalescent macules ranging in size from pinpoint to $1 \mathrm{~cm}$ over lower lips, lower labial mucosa, bilateral angles of eyes, below nose and bilateral palms and soles as shown in Figures 1-4.

Patient was admitted at surgical department with the history of abdominal pain, vomiting and blood mixed stool for one month. Jejuno-jejunal intussusception was diagnosed and laparotomy was done. There were 


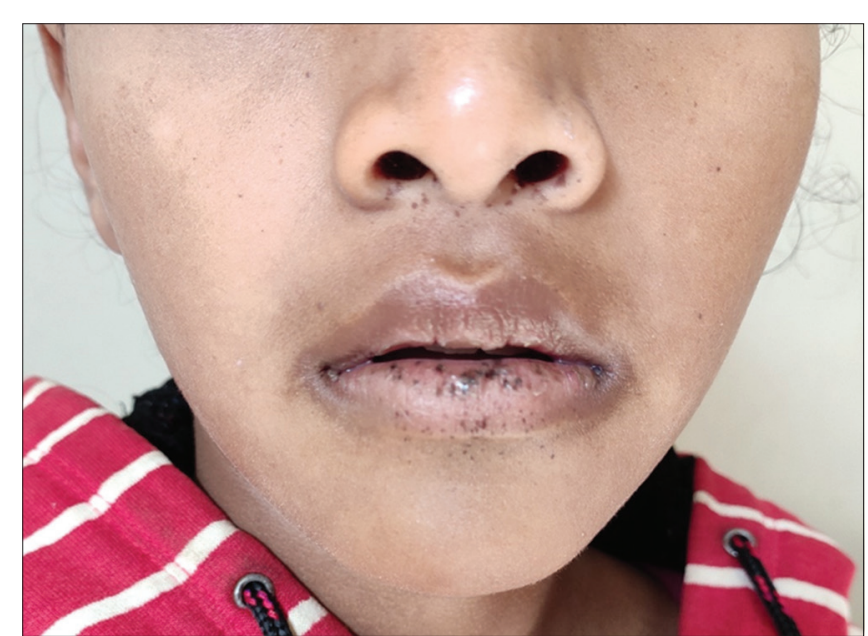

Figure 1: multiple lentigenes over the lips and nostril

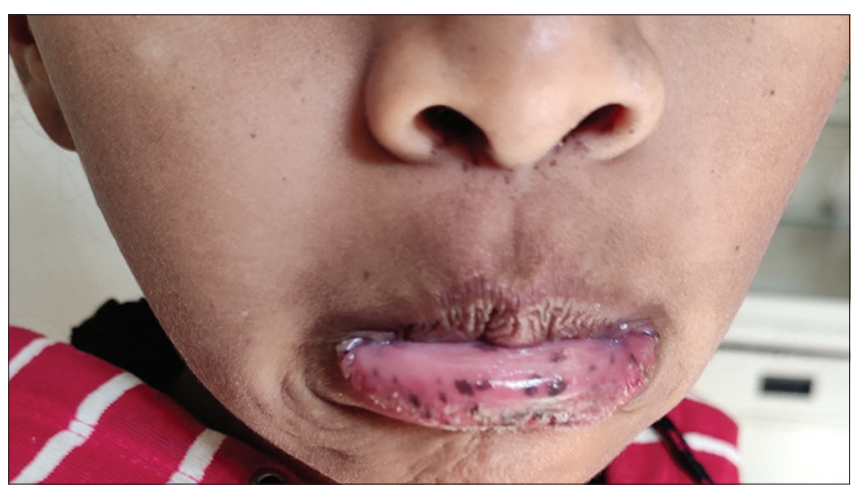

Figure 2: Multiple lentigenes over labial mucosa

five cauliflower like polyps at different sites within the jejunum. Reduction of intussusception was done along with polypectomy. Biopsy report revealed polypoidal mass with villous architecture having central fibrovascular core and back-to-back glands with little intervening stroma with lining of villi and glands by columnar cells showing nuclear stratification suggestive of tubulovillous adenoma. Patient was also operated 5 years back for the same problem. Complete blood count, renal function test, peripheral blood smear and serology reports were normal. Both CEA and AFP were within normal limit. Also, there were no mutation in STK11 gene, BRAF and APC gene. Patient's maternal grandfather had undergone some operation of gastrointestinal tract while he was 65 years old. Similarly, her first cousin was operated for similar problem on $30^{\text {th }}$ day of birth. However, they did not have pigmented lesions till date and the detailed reports couldn't be traced.

This case is reported as it is a very rare disease encountered only once in a while during practice and palmoplanter involvement is another rare finding in peutz-jeghers syndrome.

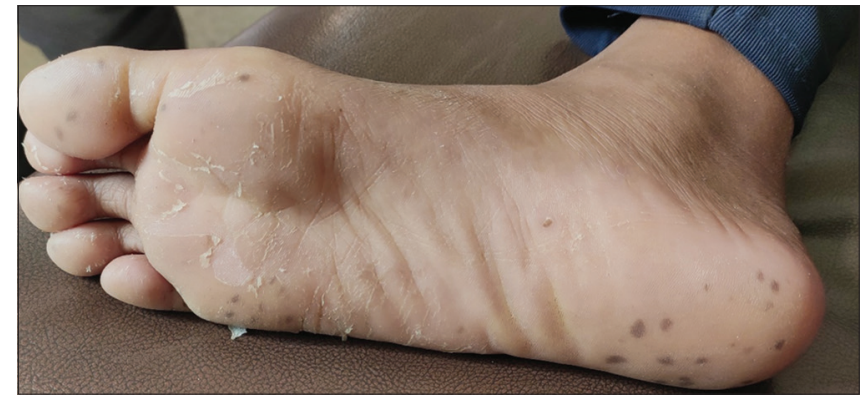

Figure 3: Hyperpigmented macules over soles

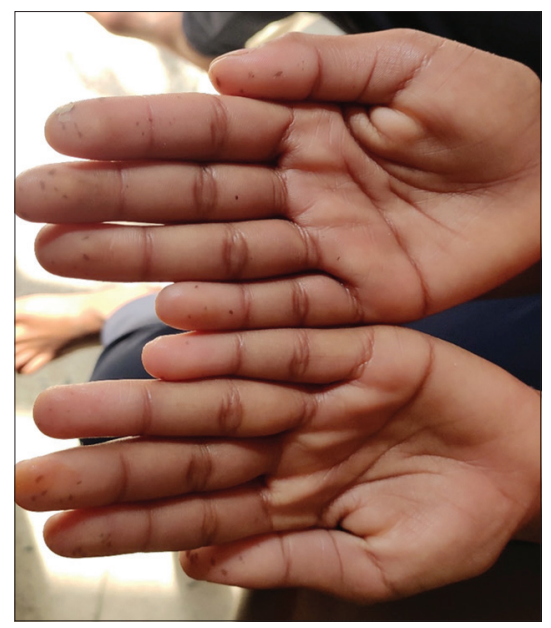

Figure 4: Hyperpigmented macules over bilateral fingers

\section{DISCUSSION}

Peutz-Jeghers syndrome is a very rare inherited disorder with features of mucocutaneous pigmentation macules around mouth and cheek, multiple polyps in the gastrointestinal tract, and recognizable family history. Condition presented with either mucocutaneous pigmentation or gastrointestinal polyps are classified as incomplete PJS. ${ }^{5,6}$ The mucocutaneous lesions generally appear during infancy and early childhood and usually disappear after puberty with persistent oral lesions. ${ }^{2}$ Similar to this, our patient also developed mucocutaneous lesion at 2 years of age. Palmoplanter involvement is relatively rare findings which was present in our patient.

The hamartomatous polyps most commonly occur in the small intestine $(78 \%)$ followed by colon $(42 \%)$, stomach $(38 \%)$, and rectum $(28 \%)^{7}$. Likewise, our patient had 5 different cauliflower like polyps in different parts of jenunum. Patients with Peutz-Jeghers syndrome often present with a history of intermittent abdominal pain due to small bowel intussusception caused by the polyps. ${ }^{8}$ Our patient had undergone surgery for intussusception twice along with polypectomy. 
Regarding the treatment of PJS, treatment is generally not necessary for mucocutaneous lesions. If however needed, laser therapy can be tried. ${ }^{9}$ For the intestinal polyps, intraoperative endoscopy followed by endoscopic polypectomy, rather than segmental resections of the bowel, have been recommended. It is recommended to do endoscopic surveillance for polyps or gastrointestinal cancer every $1-2$ years from the age of 25 years. ${ }^{10}$ About 50 percent of the patients undergoes 2 or more laparotomies. ${ }^{11}$ Also, our patient underwent laparotomy twice till the age of 10 years.

\section{REFERENCES}

1. Shivaswamy KN, Shyamprasad AL, Sumathy TK and Ranganathan C. Peutz-Jeghers syndrome with prominent palmoplantar pigmentation. Indian Journal of Dermatology, Venereology, and Leprology. 2008;74(2):154.

https://doi.org/10.4103/0378-6323.39705

2. Choudhury S, Das A, Misra P, Ray U and Sarangi S. Peutzjeghers syndrome: a circumventable emergency. Indian journal of dermatology. 2018;63(2):168.

3. Sinha N, Chatterjee $U$ and Sarkar $S$. Jejunal carcinoma in a patient with Peutz-Jeghers syndrome. Canadian Journal of Surgery. 2009;52(6): E299.

4. Bhattacharya S, Mahapatra SR, Nangalia R, Palit A, Morrissey JR, Ruban E, et al. Melaena with Peutz-Jeghers syndrome: a case report. Journal of medical case reports.
2010;4(1):44.

https://doi.org/10.1186/1752-1947-4-44

5. Kopacova M, Tacheci I, Rejchrt S and Bures J. Peutz-Jeghers syndrome: diagnostic and therapeutic approach. World journal of gastroenterology: WJG. 2009; 21;15(43):5397.

https://doi.org/10.3748/wjg.15.5397

6. Beggs AD, Latchford AR, Vasen HF, Moslein G, Alonso A, Aretz S, et al. Peutz-Jeghers syndrome: a systematic review and recommendations for management. Gut. 2010;59(7):975-986. https://doi.org/10.1136/gut.2009.198499

7. Lynch HT, Lynch JF, Lynch PM and Attard T. Hereditary colorectal cancer syndromes: molecular genetics, genetic counseling, diagnosis and management. Familial cancer. 2008;7(1):27-39. https://doi.org/10.1007/s10689-007-9165-5

8. Rufener SL, Koujok K, McKenna BJ and Walsh M. Small bowel intussusception secondary to Peutz-Jeghers polyp. Radiographics. 2008;28(1):284-288.

https://doi.org/10.1148/rg.281075092

9. Li Y, Zeng Q, Liao Z, Zhang G, Xiao R and Wen H. Peutz-Jeghers syndrome and family survey: a case report. International journal of clinical and experimental pathology. 2013;6(5):982.

10. Dunlop MG. Guidance on gastrointestinal surveillance for hereditary non-polyposis colorectal cancer, familial adenomatous polypolis, juvenile polyposis, and Peutz-Jeghers syndrome. Gut. 2002; 51(suppl 5): v 21-27.

https://doi.org/10.1136/gut.51.suppl_5.v21

11. Homan $M$, Dolenc Strazar $Z$ and Orel R. Peutz-Jeghers syndrome. A case report. Acta Dermatovenerol Alp Panonica Adriat. 2005;14(1):26-29.

\footnotetext{
Author's contribution:

PP- Concept and design of the study, manuscript preparation, statistically analyzed and interpreted, Critical revision of the manuscript; RJ- Concept and design of the study, critical revision of manuscript and review of the study.

Work attributed to:

Department of Dermatology, Kanti Children's Hospital, Nepal.

Orcid ID:

Dr. Pratima Poudel- (1) https://orcid.org/0000-0001-5725-187X

Dr. Roushan Jahan- (i) https://orcid.org/0000-0001-9470-6765

Source of Funding: None, Conflict of Interest: None.
} 